\title{
Biopolítica, vida cotidiana e interculturalidad: la clase de inglés como un espacio emancipatorio que da solución al conflicto intercultural bilingüe en un colegio público de Bogotá ${ }^{1}$
}

\section{Biopolitics, Everyday Life and Interculturalism: Teaching English from the Tikuna Myths for the Solution to Intercultural Bilingual Conflict in a School in Bogota}

\author{
Ronald Fernando Quintana-Arias ${ }^{2}$ \\ Carol Lizeth Bello-Serna ${ }^{3}$
}

\begin{abstract}
Citation/ Para citar este Artículo: Quintana-Arias, R. F. y Bello-Serna, C. L. (2020). Biopolítica, vida cotidiana e interculturalidad: la clase de inglés como un espacio emancipatorio que da solución al conflicto intercultural bilingüe en un colegio público de Bogotá. Colomb. Appl. Linguistic. J., 22(2), pp. 127-141.

Received: 22-Dec.-2019 / Accepted: 20-Oct.-2020

DOI: https://doi.org/10.14483/22487085.15765
\end{abstract}

\section{Resumen}

Con el objetivo de evidenciar la enseñanza del inglés como una herramienta que permite dar solución al conflicto intercultural bilingüe, al reconocer la identidad individual y colectiva local de 20 estudiantes de un colegio público de Bogotá durante el año 2019, se realizaron siete sesiones con una metodología de estudio de caso de enfoque participativo y de tipo descriptivo con herramientas etnográficas analizadas bajo dos categorías teóricas. Los resultados exponen un conflicto intercultural bilingüe entre inglés-lenguas locales (español-Tikuna), en el que la enseñanza del primero tiene el potencial para dar solución a conflictos ambientales y fomentar otras representaciones del mundo. El análisis a través de las categorías de biopolítica y vida cotidiana evidenció microrevoluciones de conducta que nacen de la interacción de cosmovisiones para generar una sociedad intercultural que revaloriza lo local sobre lo global. Se concluye que, en el contexto de la investigación, la clase de inglés es un escenario intercultural por naturaleza en el que los docentes promueven la adquisición de una competencia comunicativa intercultural y se forjan tejidos interdisciplinares que generan glocalización a través de la educación y el currículo.

Palabras clave: comunicación intercultural, conflicto ambiental, conflicto intercultural bilingüe, educación intercultural, multiculturalismo, sociolingüística

\footnotetext{
1 Artículo presentado para la modalidad de grado de producción académica del Proyecto de Licenciatura en Educación Básica con Énfasis en Inglés (LEBEI) de la Universidad Distrital Francisco José de Caldas bajo el marco del Acuerdo 038 del 2015.

2 Licenciado en Biología, Magíster en Desarrollo Sustentable y Gestión Ambiental, concursante a Doctor en Estudios Sociales. Universidad Distrital Francisco José de Caldas. ORCID (iD: https://orcid.org/0000-0002-3691-3464. ron902102004@gmail.com 3 Licenciada en Educación Básica con Énfasis en Inglés. Universidad Distrital Francisco José de Caldas. ORCID iD: https://orcid. org/0000-0002-5427-1389. cbcarolblbello@gmail.com
} 


\section{Abstract}

Based on the objective of evidencing the teaching of English as a tool that allows providing a solution to the intercultural bilingual conflict by recognizing the individual and collective local identity of 20 students of a public school in Bogota in 2019, seven sessions are conducted with a case study methodology using a descriptive participatory approach and ethnographic tools which are analyzed under two theoretical categories. The results expose an intercultural bilingual conflict between English-local languages (SpanishTikuna), in which the teaching of English has the potential to provide a solution to environmental conflicts and foster other representations of the world. The analysis through the categories of biopolitics and daily life evidenced behavioral micro-revolutions that are born from the interaction of worldviews that generate an intercultural society that revalues the local over the global. It is concluded that, in the context of the research, the English class is an intercultural scenario by nature, which, with teachers who promote the acquisition of intercultural communicative competence, forges interdisciplinarity, generating glocalization through education and curriculum.

Keywords: intercultural communication, environmental conflict, intercultural bilingual conflict, intercultural education, multiculturalism, sociolinguistics

\section{Introducción}

El conflicto en la educación bilingüe intercultural en un país en el que un grupo busca la homogeneización cultural (Serrano, 2008) a través de políticas educativas y sociales que responden a un enfoque asimilacionista e ignoran la existencia y las formas históricas culturales (Rother, 2005), ha generado una tensión entre la globalización, la educación y el medio ambiente. De ahí que la mayoría de personas que viven en ciudades latinoamericanas ignoren la existencia y las características culturales que pertenecen a su país: debido a la falta de aplicación de instrumentos de sensibilización que expongan la diversidad cultural local en la ciudad (Guido, 2013).

La tensión entre la globalización y la educación ha reducido la diversidad cultural al generar sociedades homogéneas que no consideran las peculiaridades de grupos étnicos o personas (Cornejo, 2012), desencadenando así la asimilación global de una cultura única (Jennings, 2011) que no salvaguarda el patrimonio inmaterial del lenguaje y la cultura en un país que se reconoce como pluriétnico y multicultural desde 1991 con la Constitución Política de Colombia.

Lo anterior se agudiza con falta de políticas públicas colombianas que protejan las lenguas tradicionales, como lo evidencia la publicación Ethnologue (Eberhard et. al, 2019; UNESCO, 2010) al exponer que en Colombia se han extinguido 21 idiomas tradicionales, en los que sobresalen las pérdidas contemporáneas de las lenguas carabayo (Amazonas), macaguaje (Amazonas), opón-carare (Santander), pijao (Tolima) y kankuamo (Costa Atlántica), lo que enmarca el reto del desarrollo de una competencia intercultural que revalorice lo local mediante el uso de herramientas que motiven a los estudiantes a visibilizar y vivir su riqueza cultural por medio de una lengua extranjera (Quintana Arias, 2020).

Dentro de este contexto se enmarca un conflicto intercultural bilingüe (CIB) o de tensiones de la enseñanza de lenguas extranjeras impuestas, como el inglés, con lenguas locales, como la indígena tikuna y el español. En este conflicto se identifica una biopolítica homogeneizadora que ha capturado expresiones culturales locales como tradiciones, creencias y formas de relacionarse con el territorio, que se han situado en la vida cotidiana y expresado con microrevoluciones de conducta que fomentan y fortalecen lo local sobre lo global, lo que hace pertinente la visibilización de las cosmoviones indígenas en contextos urbanos como el de Bogotá.

Dicho de otra manera, la problemática de la enseñanza de una lengua extranjera que da más importancia al desarrollo de la competencia lingüística que a la intercultural (Omaggio, 2001) es a su vez una oportunidad que implica el reconocimiento mutuo de los miembros sociales y su participación en las decisiones políticas (Cornejo, 2012). De esta manera, la globalización es una oportunidad para el reconocimiento de la diversidad 
(Soto, 2015), lo que hace pertinente la pregunta: ¿de qué manera la enseñanza de la lengua inglesa y los mitos Tikuna, desde el enfoque intercultural, representan una herramienta que puede mitigar el conflicto intercultural bilingüe en un grupo de estudiantes de grado 11 de un colegio público de Bogotá?

El objetivo del estudio estuvo orientado a evidenciar la lengua inglesa como una herramienta que permite dar solución al conflicto intercultural bilingüe, al reconocer la identidad cultural local. Este artículo se refiere a la experiencia relacionada con la biopolítica, la vida cotidiana y la interculturalidad, y su incidencia en la enseñanza del inglés desde los mitos Tikuna, para dar solución al conflicto intercultural bilingüe en un colegio público de Bogotá.

Lo anterior permite trascender la utopía de lo multicultural para identificar valores interculturales a través de un diálogo interepistémico entre la interculturalidad y la enseñanza, que posibilitan la transición de la pedagogía crítica hacia una pedagogía descolonizadora que reivindica campos de ser, poder y saber en la vida, a través de las categorías de la biopolítica y la vida cotidiana.

La categoría de la biopolítica se ve como el proceso en el que la vida es capturada por la política a través de cinco perspectivas:

a. La escuela desde Foucault (1992) como un espacio de 'biopoder' y 'biopolítica' donde la educación cumple un fin político, que en este contexto obedece a la imposición de la enseñanza de la lengua inglesa sobre las locales.

b. El conflicto educativo intercultural desde Rother (2005), donde una cultura tiene un poder simbólico sobre el resto de culturas que están presentes, como se evidencia en la tensión inglés-español-tikuna.

c. La pluralidad analizada desde lo que Tassin (2001) definió como el reconocimiento de la diversidad y la diferencia de las comunidades que tienen un actuar político en un mundo común. d. La multiculturalidad vista desde lo que Kymlicka E Castells (1996) definieron como sociedades paralelas o grupos culturales y nacionales que coexisten en un escenario en el que reconocen la diferencia y se respetan.

e. La pedagogía vista desde Durkheim (2014), refiriéndose a las relaciones individuo-sociedad, ciencia-práctica y la naturaleza de la moralidad y del entendimiento.

La categoría de la vida cotidiana es una oportunidad pedagógica para comprender al sujeto que rompe con la tradición cartesiana moderna y que presupone la vigencia de un sujeto que se mantiene inalterable a la experiencia. Para ello se llevó a cabo el debate desde dos perspectivas teóricas: (i) La vida cotidiana desde Bégout (2005) como el esquematismo trascendental de la cotidianización que implica analizar la causalidad en la emergencia de los contrapoderes, la comprensión de la historia y la historicidad humana, así como la posibilidad que esta tiene, según Useche y Pérez (2019), para generar cambios en las personas desde la microética (posturas éticas a nivel personal) y la micropolítica (posturas políticas a nivel personal), que lleven a generar microrevoluciones (cambios de conductas a nivel personal). ii) La interculturalidad contemplada como sociedades integradas desde lo que Soto (2008) define como culturas comprometidas en un diálogo de saberes, y desde lo que Tubino (2003) define como una propuesta ética en un mundo que está más interconectado tecnológicamente pero incomunicado interculturalmente.

De esta manera, el conocimiento hacia personas de otras culturas como sujetos cuyas cualidades son descubiertas en lugar de ser estereotipadas (Byram et. al, 2002), hacen del conocimiento sobre la enseñanza de contextos culturales locales a través del idioma inglés un aprendizaje guiado que despierta la microética, la micropolítica y las microrevoluciones como formas de combatir la extinción gradual y sistemática de la riqueza pluriétnica y multicultural local que se ha generado por el desplazamiento de diferentes comunidades a la ciudad (CNMH, 2014). 
La competencia intercultural y el inglés enmarcan una habilidad comunicativa para que el estudiante se sienta a gusto y cómodo (Alonso, 2006) al fomentar relaciones interpersonales que fortalezcan la tolerancia, el respeto y revolucionen estilos de vida (Rojas et. al, 2007), identificando las maneras de mejorar su nivel de vida y el de la comunidad con la cultura de origen y el conocimiento de otras culturas (Soto, 2008). Esta competencia es clave dentro del contexto educativo, ya que ayuda a reducir la homogeneización cultural, como lo corroboran Byram et. al (2002), al concluir que "el rol de la educación debe estar basado en descubrir cualidades de los demás en lugar de discriminarlas" (p. 35), lo que es ratificado por Majhanovich et. al (2009), quienes le dan importancia a "la labor social de la educación que genera comunicación transcultural en ambientes educativos" (p. 154).

La enseñanza del inglés a través de aspectos socioculturales es una forma de abordar la formación de una identidad propia y el reconocimiento de las culturas de forma respetuosa

(Morimoto et. al, 2015), lo que hace de la educación intercultural un contexto en el que la comunicación cobra sentido (Albó, 2002) y expone las diferencias culturales (Quintero y Torres, 2010) para solucionar los problemas de estas diferencias (Paricio Tato, 2014), desde una mirada comunicativa que fomente la formación integral y ciudadana (Rojas Fabris, 2018).

En este sentido, autores como Gyepi-Garbrah (2010) consideran esencial la comunicación entre las culturas en el programa comunitario en Winnipeg, Canadá, para facilitar las relaciones entre los pueblos aborígenes y los nuevos pobladores dentro de la ciudad. Esto evidencia que los diálogos permiten el aprendizaje, rompen estereotipos y fomentan la paz. Asimismo, es importante resaltar que la educación intercultural no solo es necesaria en instituciones en las cuales hay estudiantes de diversos orígenes o etnias, sino en todas las instituciones, pues representa un factor clave para evitar la homogeneización cultural y así poder preservar las culturas locales (Cornejo, 2012).
Por todo lo anterior, nuestro objetivo es evidenciar la lengua inglesa como una herramienta que permite dar solución a distintas problemáticas que se originan por el conflicto intercultural bilingüe, desde mitos Tikuna que permitan reconocer la identidad cultural local, a través de una metodología de estudio de caso con un enfoque participativo de tipo descriptivo realizada en siete sesiones en las que se estudiaron las narraciones de 20 estudiantes de grado 11 de un colegio público de Bogotá, sobre las apropiaciones de otras formas históricas culturales (mitos) para relacionarse con el territorio de una de las etnias indígenas que se encuentran en Colombia.

\section{Metodología}

Se realizó un estudio de caso con un enfoque participativo de tipo descriptivo que fue útil para contrastar y generar teoría (Eisenhardt, 1989), a través de mitos Tikuna que llevaron a exponer a la lengua inglesa como una herramienta que permite dar solución al conflicto intercultural bilingüe, al reconocer la identidad cultural local en un grupo de estudiantes de grado 11 de un colegio público de Bogotá. Esto, desde un enfoque intercultural que aborda los mitos Tikuna y reconoce la identidad del individuo en "una cognición compartida que se proyecta en sus acciones y producciones" (Luque, 2008, p. 8).

Las actividades y los datos que se recolectaron al final de las intervenciones tuvieron como eje articulador el trabajo Plantas Medicinales del Amazonas (PMA), realizado por Quintana Arias (2015), para referirse a la relación individuosociedad (Durkheim, 2014) y trasladar la enseñanza del inglés desde el interculturalismo funcional, que va en función del sistema económico, hacia un interculturalismo crítico o proyecto éticopolítico (Tubino, 2003). Asimismo, el análisis de las categorías de biopolítica y vida cotidiana expuso el conflicto intercultural de enseñar otra lengua oficial de la ONU como el inglés (ONU, 2014) en un país que tiene una gran riqueza lingüística y prioriza la enseñanza de una lengua no local, como un medio que permite fomentar glocalización o revalorización de lo local en el marco de la globalización. 
Lo anterior permitió promover en los estudiantes la apropiación de la diversidad cultural de una etnia indígena colombiana por medio de mitos o formas históricas culturales para relacionarse con el territorio, a través del análisis de las categorías de biopolítica y vida cotidiana en siete sesiones en las que se usaron herramientas etnográficas como entrevistas y diarios de campo.
El trabajo se realizó con una población originaria de diversas partes del país y cuyo desplazamiento en algunos casos obedeció a las dinámicas históricas propias del conflicto armado. Cabe resaltar que la cantidad de 20 estudiantes con edades que oscilaban entre 15 y 17 años obedeció a la disponibilidad autorizada por la dirección del colegio para participar en la propuesta pedagógica que será descrita en la Tabla 1.

Tabla 1. Propuesta pedagógica.

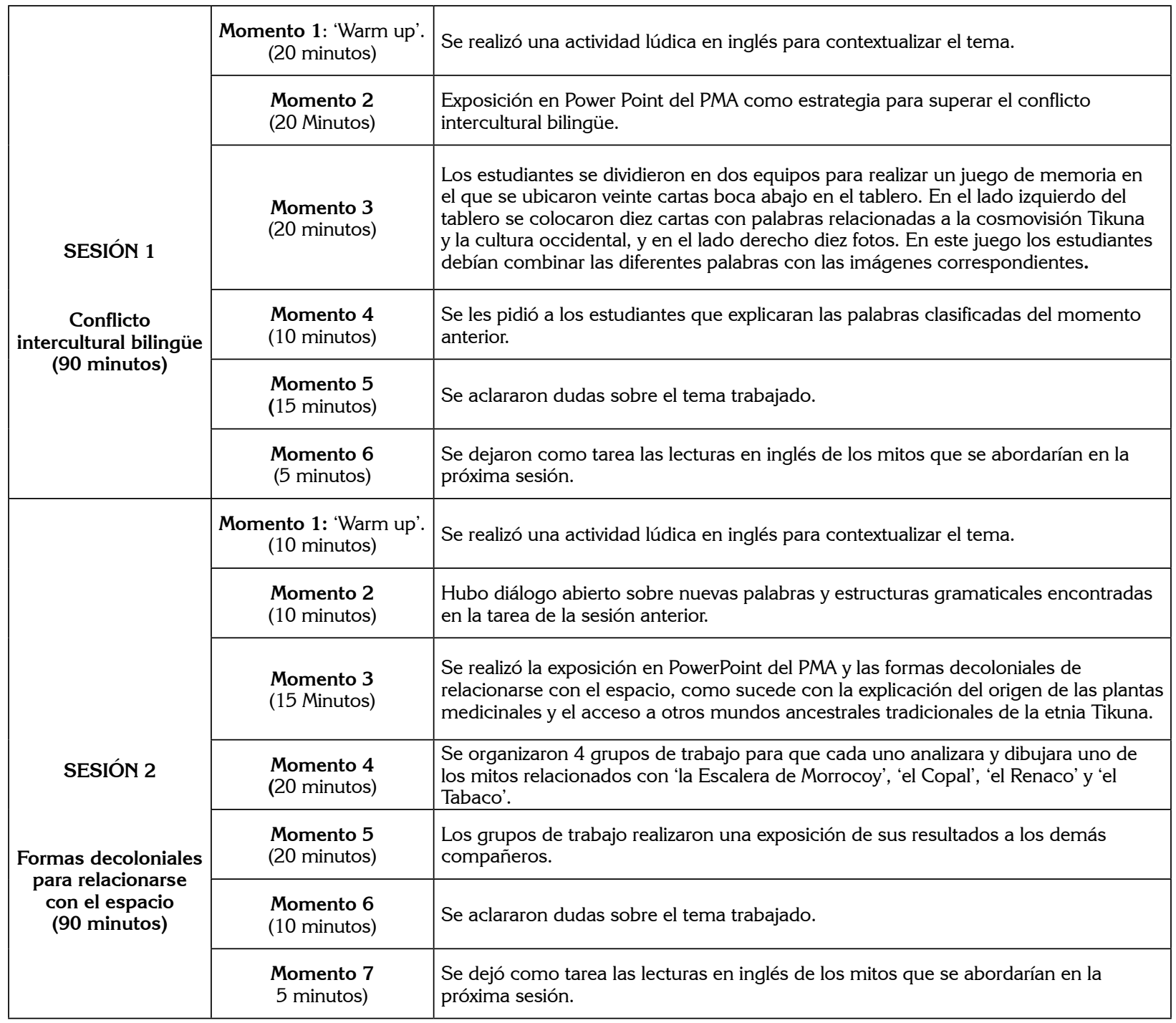

Continúa... 


\begin{tabular}{|c|c|c|}
\hline \multirow{7}{*}{$\begin{array}{c}\text { La interculturalidad } \\
\text { y el conocimiento } \\
\text { local sobre } \\
\text { plantas que curan } \\
\text { enfermedades (90 } \\
\text { minutos) }\end{array}$} & \begin{tabular}{|c|} 
Momento 1: 'Warm up'. \\
(10 minutos)
\end{tabular} & Se realizó una actividad lúdica en inglés para contextualizar el tema. \\
\hline & $\begin{array}{l}\text { Momento } 2 \\
\text { (15 minutos) }\end{array}$ & $\begin{array}{l}\text { Hubo un diálogo abierto sobre nuevas palabras y estructuras gramaticales } \\
\text { encontradas en la tarea de la sesión anterior. }\end{array}$ \\
\hline & $\begin{array}{l}\text { Momento } 3 \\
\text { (15 Minutos) }\end{array}$ & $\begin{array}{l}\text { Se realizó la exposición en PowerPoint del PMA y las maneras como los indígenas } \\
\text { han aportado al conocimiento sobre plantas medicinales. }\end{array}$ \\
\hline & $\begin{array}{l}\text { Momento } 4 \\
\text { (20 minutos) }\end{array}$ & $\begin{array}{l}\text { Se organizaron } 2 \text { grupos de trabajo para que cada uno analizara y discutiera los } \\
\text { valores de los mitos de la 'Lupuna Roja' y la 'Pona Barriguda'. }\end{array}$ \\
\hline & $\begin{array}{l}\text { Momento } 5 \\
\text { (10 minutos) }\end{array}$ & $\begin{array}{l}\text { Un representante de cada grupo expuso sus resultados para establecer cuáles fueron } \\
\text { las ideas principales. }\end{array}$ \\
\hline & $\begin{array}{l}\text { Momento } 6 \\
\text { (15 minutos) }\end{array}$ & Se aclararon dudas sobre el tema trabajado. \\
\hline & $\begin{array}{c}\text { Momento } 7 \\
\text { (5 minutos) } \\
\text { Tarea }\end{array}$ & $\begin{array}{l}\text { Se organizaron tres grupos de trabajo denominados 'Huito', 'Coca' y ‘Punga', para que } \\
\text { hicieran una representación teatral en inglés de las tres historias en la siguiente sesión. }\end{array}$ \\
\hline \multirow{5}{*}{$\begin{array}{c}\text { El diálogo } \\
\text { intercultural y las } \\
\text { nuevas formas de } \\
\text { ver el mundo } \\
\text { (90 minutos) }\end{array}$} & $\begin{array}{l}\text { Momento 1: 'Warm up' } \\
\text { (10 minutos) }\end{array}$ & Se realizó una actividad lúdica en inglés para contextualizar el tema. \\
\hline & $\begin{array}{l}\text { Momento } 2 \\
(15 \text { minutos })\end{array}$ & $\begin{array}{c}\text { Hubo un diálogo abierto sobre nuevas palabras y estructuras gramaticales } \\
\text { encontradas en la tarea de la sesión anterior. }\end{array}$ \\
\hline & $\begin{array}{l}\text { Momento } 3 \\
\text { (15 Minutos) }\end{array}$ & $\begin{array}{c}\text { Se realizó la exposición en PowerPoint del PMA y la importancia de un mundo que } \\
\text { surge desde diálogos interepistémicos e interculturales. }\end{array}$ \\
\hline & $\begin{array}{c}\text { Momento } 4 \\
\text { (30 minutos) } \\
\text { Haciendo Teatro } \\
\end{array}$ & $\begin{array}{l}\text { Los estudiantes hicieron presentaciones en inglés de los grupos 'Huito', 'Coca' y ‘Punga', } \\
\text { en las que contaron a sus compañeros cómo interpretaron y usaron los símbolos de las } \\
\text { historias en sus vidas, así como el valor que tienen esas plantas para la etnia Tikuna. }\end{array}$ \\
\hline & $\begin{array}{l}\text { Momento } 5 \\
\text { (20 minutos) }\end{array}$ & Se aclararon dudas sobre el tema trabajado. \\
\hline \multirow{6}{*}{$\begin{array}{c}\text { El idioma inglés en } \\
\text { la vida diaria y la } \\
\text { ficcionalización de la } \\
\text { realidad } \\
(90 \text { minutos })\end{array}$} & $\begin{array}{l}\text { Momento 1: ‘Warm up'. } \\
\text { (10 minutos) }\end{array}$ & Se realizó una actividad lúdica en inglés para contextualizar el tema. \\
\hline & $\begin{array}{l}\text { Momento } 2 \\
\text { (10 minutos) }\end{array}$ & Hubo un diálogo abierto sobre nuevas palabras y estructuras gramaticales. \\
\hline & $\begin{array}{l}\text { Momento } 3 \\
\text { (15 Minutos) }\end{array}$ & $\begin{array}{l}\text { Se realizó una exposición en PowerPoint del PMA y la manera como el uso del idioma } \\
\text { inglés es una línea de fuga que permite darle voz a los no visibilizados por el conflicto } \\
\text { intercultural bilingüe. }\end{array}$ \\
\hline & \begin{tabular}{|c|} 
Momento 4 \\
(20 minutos) \\
Terminando una historia \\
\end{tabular} & $\begin{array}{l}\text { Se organizaron } 6 \text { grupos de trabajo en los que los estudiantes leyeron el mito } \\
\text { incompleto del 'Palo de Sangre', para que ellos lo completaran con su propio final. }\end{array}$ \\
\hline & \begin{tabular}{|c|} 
Momento 5 \\
(20 Minutos) \\
Comparando realidades \\
\end{tabular} & $\begin{array}{l}\text { Se socializó el verdadero final del mito y se comparó con los otros para evidenciar } \\
\text { qué y cómo cada persona exponía una posible realidad. }\end{array}$ \\
\hline & $\begin{array}{c}\begin{array}{l}\text { Momento } 6 \\
(15 \text { minutos })\end{array} \\
\end{array}$ & Se aclararon dudas sobre el tema trabajado. \\
\hline \multirow{5}{*}{$\begin{array}{c}\text { La cosmovisión } \\
\text { Tikuna y el conflicto } \\
\text { intercultural bilingüe } \\
\text { (90 minutos) }\end{array}$} & $\begin{array}{c}\text { Momento 1: 'Warm up'. } \\
\text { (10 minutos) }\end{array}$ & Se realizó una actividad lúdica en inglés para contextualizar el tema. \\
\hline & $\begin{array}{l}\begin{array}{l}\text { Momento } 2 \\
\text { (15 minutos) }\end{array} \\
\end{array}$ & Hubo un diálogo abierto sobre nuevas palabras y estructuras gramaticales. \\
\hline & $\begin{array}{l}\text { Momento } 3 \\
\text { (20 Minutos) }\end{array}$ & $\begin{array}{l}\text { Se realizó la exposición en PowerPoint del PMA y la manera cómo la cosmovisión Tikuna } \\
\text { hace parte de la interculturalidad colombiana que, al ser trabajada desde la escuela, hace } \\
\text { frente al conflicto intercultural bilingüe en un país pluriétnico y multicultural. }\end{array}$ \\
\hline & $\begin{array}{c}\text { Momento } 4 \\
\text { (30 minutos) } \\
\text { Póster }\end{array}$ & $\begin{array}{l}\text { Se organizaron grupos de trabajo en los que los estudiantes hicieron un póster } \\
\text { (trabajo en grupo) sobre lo que pensaban de la mitología Tikuna, la interculturalidad } \\
\text { colombiana y el conflicto intercultural bilingüe. }\end{array}$ \\
\hline & $\begin{array}{l}\text { Momento } 5 \\
\text { (15 minutos) }\end{array}$ & Se aclararon dudas sobre el tema trabajado. \\
\hline SESIÓN 7 & \multirow{2}{*}{\multicolumn{2}{|c|}{$\begin{array}{l}\text { Espacio de entrevistas para evaluar los impactos de la propuesta de enseñanza del inglés que buscó dar } \\
\text { solución al conflicto intercultural bilingüe desde un enfoque intercultural (mitos Tikuna). }\end{array}$}} \\
\hline $\begin{array}{l}\text { El idioma inglés } \\
\text { como herramienta } \\
\text { para la solución del } \\
\text { conflicto intercultural } \\
\text { bilingüe (45 minutos) }\end{array}$ & & \\
\hline
\end{tabular}

Fuente: elaborado por autores. 


\section{Resultados}

Los resultados evidencian la enseñanza de la lengua inglesa como una herramienta que permite dar solución al conflicto intercultural bilingüe, desde actos semiológicos de la vida cotidiana o las maneras como el sujeto representa al mundo y los actos que suceden en su vida (Ruiz, 2016), al formar estudiantes críticos que no son sólo producto sino productores del lenguaje.

De esta manera, los mitos Tikuna permitieron reconocer la identidad individual y colectiva de estudiantes de grado 11 de un colegio público de Bogotá, a través de siete sesiones divididas en: (1) conflicto intercultural bilingüe y su relación con el medio ambiente; (2) formas decoloniales para relacionarse con el espacio; (3) la interculturalidad y el conocimiento local sobre plantas que curan enfermedades; (4) el diálogo intercultural y las nuevas formas de ver el mundo; (5) el idioma inglés en la vida diaria y la ficcionalización de la realidad; (6) la cosmovision Tikuna y el conflicto intercultural bilingüe; (7) el idioma inglés como herramienta para la solución del conflicto intercultural bilingüe.

\section{Sesión 1. Conflicto intercultural bilingüe y su relación con el medio ambiente}

Los estudiantes manifiestan que el aprendizaje del inglés es una herramienta que les permite interpretar un mundo globalizado en el que la comprensión de las culturas se facilita gracias a la música, los libros, la televisión, las películas, la internet, etc., así como por un sistema de valores culturales y de mercado que enmarcan unas actitudes positivas o negativas hacia el aprendizaje de la lengua.

Yo había escuchado antes que en Colombia se hablan muchos idiomas y no sabía que eso se podía relacionar con el conflicto intercultural bilingüe y que desde el inglés se puede aprender sobre cosas de esos idiomas de Colombia. (Entrevista realizada a estudiante)

Profe, cuando nos habla de todo eso de los indios me parece muy bonito, yo he visto películas sobre ese tema y siempre veo que ellos tienen mucha sabiduría que en esta cultura no se tiene en cuenta. Siempre pensé que el inglés era para el ICFES o para entender música, pero jamás pensé que podíamos aprender cosas de nuestras culturas indígenas a través de su enseñanza. (Entrevista realizada a estudiante)

Los resultados de la actividad evidenciaron que la enseñanza del inglés puede ser usada más allá de un enfoque asimilacionista que ignora la existencia y las formas históricas culturales de relacionarse con el territorio, para incluir de conceptos y cosmovisiones de culturas locales como la Tikuna, lo que convierte a la enseñanza del inglés en una plataforma para la formación intercultural y la revalorización de las culturas locales.

\section{Sesión 2. Formas decoloniales para relacionarse con el espacio}

Las formas decoloniales despertaron un gran interés en los estudiantes, ya que estas palabras y conceptos no pueden ser traducidas por otras culturas y deben ser pronunciadas y escritas en el idioma tradicional o en español. Los estudiantes indicaron que para ellos las formas tradicionales de relacionarse con el territorio, desde los mitos de 'la Escalera de Morrocoy', 'el Copal', 'el Renaco' y 'el Tabaco', no son visibilizadas en la ciudad ni en lo que ellos han conocido de otros lugares de Colombia.

Profe, las historias que nos cuenta nos hablan del amor hacia el territorio y nos dicen otras formas de cómo se originaron la cosas y otras formas para relacionarse con las plantas y animales. Es muy bacano que en Colombia haya todas estas historias, qué lástima que no se enseñen desde antes y que el ser humano esté acabando con los ríos, los árboles, los animales y las culturas indígenas. (Entrevista realizada a estudiante) Yo no tenía claro que algunas cosas no deben pronunciarse en otros idiomas, acá acostumbramos a decir las cosas como suenan en otros países, pero saber de estas historias y estas personas no solo me enseña a respetar su idioma sino el mío [...]. También nos habla sobre la riqueza que tenemos como país y la riqueza que tenemos por la biodiversidad. (Entrevista realizada a estudiante) 
Lo anterior evidencia valores interculturales que se manifiestan en los mitos abordados y en la cotidianidad de los estudiantes como el amor, la solidaridad y el trabajo en equipo, pero pareciera que el modelo de educación no sopesa el enfoque eurocéntrico que solo pretende repetir lo que se hace en otros países sin tener en cuenta las realidades sociales y económicas, así como la riqueza histórica y lingüística local.

De esta manera, la exposición de los estudiantes sobre los dibujos de los mitos 'la Escalera de Morrocoy', 'el Copal', 'el Renaco' y 'el Tabaco', tuvo como núcleo común el conflicto de relacionarse con el espacio bajo dos visiones contrarias: por un lado, la del Hombre (humanidad) como parte de la naturaleza que enfatiza la armonía y el equilibrio, y por el otro, la del Hombre dueño de la naturaleza que domina y genera problemáticas ambientales como la deforestación, la pérdida de los páramos, los humedales, la calidad del agua, la soberanía alimentaria, así como la pérdida de diferentes grupos indígenas e idiomas locales.

\section{Sesión 3. La interculturalidad y el conocimiento local sobre plantas que curan enfermedades (90 minutos)}

La manera como los indígenas han aportado al conocimiento sobre plantas medicinales abordada en las sesiones anteriores y reforzada con los mitos de la 'Lupuna roja' y la 'Pona Barriguda' evidenciaron el desarrollo de la competencia intercultural como eje conductor de la competencia lingüística en el aprendizaje del idioma inglés.

Aprender inglés aprendiendo cosas de los indígenas es muy cool, ahora entiendo a mi mamá cuando me cuenta que en el campo la gente sabe mucho de la naturaleza, y yo ahora le puedo decir cosas en español, inglés y tikuna que ella no sabía sobre historias y plantas. (Entrevista realizada a estudiante)

Yo sé que los indígenas saben mucho de medicina, en mi casa usamos plantas medicinales que mi mamá tiene en la casa como yerbabuena, albahaca [...] saber sobre cómo algunas poblaciones hablan del origen de las plantas que ellos usan me parece muy bueno, sus historias dejan enseñanzas sobre el amor, el trabajo con la naturaleza y, como nos decía usted, otras formas para ver el mundo. (Entrevista realizada a estudiante)

Los estudiantes no solo conocieron nuevos conceptos y palabras en tikuna y en inglés, sino que también reafirmaron valores y costumbres a los que la realidad de la ciudad no les da importancia, lo que genera una nueva forma de comunicación contemporánea entre el español, el inglés y el tikuna en la que, a través de la enseñanza del inglés, se aprendió sobre otras culturas, el lenguaje y la realidad de culturas locales.

\section{Sesión 4. El diálogo intercultural y las nuevas formas de ver el mundo (90 minutos)}

Contemplar otras cosmovisiones y representarlas a través del teatro de los mitos del 'Huito', 'Coca' y 'Punga', significó hacer del escenario de enseñanza del inglés un espacio de diálogos interepistémicos e interculturales, ya que estos mitos estaban relacionados con el origen de la etnia Tikuna.

\footnotetext{
Representar estas historias me recuerda cuando el profe de sociales de primaria nos hacía representar el descubrimiento de América. Esto me hace preguntarme la manera cómo a través del lenguaje y las palabras podemos descubrir cosas; estas historias me enseñan otras cosas que no sabía que se podían aprender en materias como el inglés. (Entrevista realizada a estudiante)

Es muy interesante ver cómo los indígenas de nuestro país se relacionan con algunas plantas y animales, me parece importante que nosotros reconozcamos estas historias ya que nos permite ver otras formas para relacionarnos mejor no sólo con las personas sino con los animales y con el medio ambiente. (Entrevista realizada a estudiante)
}

Lo anterior evidencia que la enseñanza del inglés desde el enfoque intercultural fortalece las relaciones interpersonales a través de la lengua materna y el inglés, posibilitando otras formas 
de ver el mundo, de concebir reglas y tradiciones locales que pueden ayudar a mejorar el nivel de vida del estudiante y el de la comunidad a través del reconocimiento intercultural.

\section{Sesión 5. El idioma inglés en la vida diaria y la ficcionalización de la realidad (90 minutos)}

A través del mito incompleto del 'Palo de Sangre' y los posibles finales, se evidenció que el idioma inglés enmarca un contexto cultural que ha permeado muchos de los aspectos de los estudiantes, ya sea en la música, el Internet o el cine, lo que hace que su enseñanza y la interculturalidad cobre sentido.

\begin{abstract}
Es interesante escuchar las narraciones de nuestros compañeros, muchos crearon finales felices para las historias [...] este tipo de actividades son muy buenas porque nos permite evidenciar, a través del inglés, el español y las palabras en lengua Tikuna, de dónde venimos y hacia dónde vamos. (Entrevista realizada a estudiante)

Cuando uno es niño siempre quiso ser un héroe de película, esta actividad me gustó porque los finales fueron muy chistosos, algunos pusieron héroes de Marvel y DC Cómics para salvar el día, yo por lo menos hablé de zombis y extraterrestres que no lograron derrotar el amor del héroe delfín rosado y su novia. (Entrevista realizada a estudiante)
\end{abstract}

Los finales que dieron los estudiantes a las historias estaban relacionados con la perspectiva y el contexto de su vida cotidiana. Sin embargo, el uso de referentes como Marvel o DC muestra que existe un componente abstracto de la significación que los hace capaces de distanciarse o acercarse a las formas preestablecidas de significado para negociar un sentido particular de elementos del mundo dados por la moda, el cine, las redes sociales, los cómics o la televisión.

De esta manera, todos los finales posibles de las historias retomaron figuras del cine norteamericano para recrear héroes y villanos, por lo que el docente debe reconocer las diferencias interculturales, así como flexibilizar, actualizar y solucionar los problemas que surgen de estas diferencias, dándole siempre valor a lo local sobre lo global.

\section{Sesión 6. La cosmovisión Tikuna y el conflicto intercultural bilingüe (90 minutos)}

La realización de los afiches en inglés sobre la mitología Tikuna y el conflicto intercultural bilingüe evidenció la posibilidad de que una lengua no nativa (inglés) en un país hispano hablante se use para el reconocimiento respetuoso de una cultura indígena local y como alternativa de solución al conflicto intercultural bilingüe.

Creo que nuestra cultura tiene muchos héroes
e historias que no se están aprovechando, me
gusta mucho que la clase de inglés sea un
espacio para aprender sobre nosotros y no para
hablar de fiestas o héroes de otros países [...]
esta actividad la hice con mi hermana menor,
y mi familia también está aprendiendo sobre la
riqueza de nuestro país. (Entrevista realizada a
estudiante)
Me gustó mucho que los pósters se hayan
hecho con mensajes de nuestra cultura, yo hice
un delfín rosado con capa porque ellos pueden
vivir tanto en el mundo de las aguas como en
el de nosotros. Los árboles y los ríos los dibujé
porque son el hogar de varios animales y
nuestro país debe cuidarlos para cuidar la vida.
(Entrevista realizada a estudiante)

La actividad fue un espacio que generó una comunicación intercultural en la que los estudiantes tuvieron la posibilidad de afirmar su identidad y desarrollar habilidades comunicativas necesarias para interactuar a través de los pósters. Este momento evidenció la transición del contexto socio-situado inicial de sistemas de evaluación establecidos, donde prevalece la postura eurocéntrica sobre lo local, hacia la emancipación de lo local sobre lo global.

En este contexto, la enseñanza del inglés en la interculturalidad es una estrategia de lenguaje que propicia lo local hacia lo global, posibilitando el empleo de la cosmovisión Tikuna en la propuesta pedagógica no solo como una manera de abordar 
el conflicto intercultural bilingüe, sino como una perspectiva para que los estudiantes se reconozcan como creadores y fuentes de mensajes que pueden dar solución a las problemáticas que tienen en su diario vivir.

\section{Sesión 7. Elidiomainglés como herramienta para la solución del conflicto intercultural bilingüe (45 minutos)}

\begin{abstract}
Yo le he enseñado cosas a mi mamá y a mi abuela sobre lo que vimos en clase, nos gustó mucho la propuesta porque aprendimos sobre los Tikuna a través del inglés, así como palabras que no se pueden traducir en otros lugares como los nombres de los árboles y los héroes de las historias [...] yo pensaba que todo sonaba más bonito en inglés, pero ahora sé decir también cosas en Tikuna y sé que nosotros tenemos cosas más bonitas e importantes que cuidar que las que se nos muestran en las películas, muchas gracias Profe. (Entrevista realizada a estudiante)

Creo que hay mucho que aprender sobre nuestro país, lo que vimos en clase lo hemos hablado en mi casa con mi familia y nos parece importante que reconozcamos nuestro país y la diversidad que tenemos, aprendí muchas cosas sobre estructuras gramaticales en inglés que antes no me interesaban, creo que educar sobre lo que nosotros tenemos despierta más interés que tratar de hacer ver lo de otros países como lo mejor. (Entrevista realizada a estudiante)
\end{abstract}

Los estudiantes manifestaron que la estrategia llevada a cabo se relacionó con su vida cotidiana a través de actos semiológicos, como la comunicación con sus padres sobre los mitos Tikuna y el reconocimiento de su identidad individual y colectiva como colombianos. De esta manera, en la propuesta se evidenciaron factores internos (conocimiento y apropiación de la cultura propia) $\mathrm{y}$ externos (interacciones entre las lenguas y las culturas) que inciden en lo afectivo y cognoscitivo para la adquisición de la competencia comunicativa en lengua extranjera.

La estrategia fomentó microrevoluciones de conducta o cambios de comportamientos, y procesos de glocalización para la recuperación, conservación y protección de "culturas" que son 'invisibilizadas' por otra dominante, y cuyo poder simbólico radica en políticas educativas que ignoran la existencia histórica local de otras formas políticas, económicas y ambientales de relacionarse con el territorio.

\section{Análisis de resultados}

Los resultados indican que el enfoque intercultural desde los mitos Tikuna para la enseñanza del inglés en los estudiantes de grado 11 de un colegio público de Bogotá fue una estrategia que encaró el enfoque asimilacionista, base del conflicto en la educación bilingüe intercultural. De esta manera, la interculturalidad es una forma de asumir el mundo en la escuela como un espacio de biopoder donde se generan actos semiológicos de la vida cotidiana (Ruiz, 2016) con una interdependencia afectivo-cognoscitiva que repercute en lo vivencial y se pone de manifiesto en la cantidad y calidad de la producción sociolingüística y la relación con el medio ambiente.

Lo anterior sopesó las posiciones arrogantes de una cultura que puede ser considerada superior a otra, al aceptar los patrones culturales locales como parte de la identidad (Key, 1998), e hizo de las clases un espacio de 'biopoder' y 'biopolítica' con un fin político (Foucault, 1992), permitiendo la transición del interculturalismo funcional o político hacia el interculturalismo crítico o ético-político (Tubino, 2003) que, al "interactuar de manera efectiva con otras culturas que reconocemos como diferentes de la propia" (Guilherme, 2004, p. 297), aumentó la visibilización de otras realidades culturales y lingüísticas locales.

Frente a la vida cotidiana los estudiantes manifestaron en las sesiones valores interculturales como el amor y la solidaridad, así como una trasformación conceptual y actitudinal que se evidenció en las dimensiones corporal, afectiva, lingüística-comunicativa, cognitiva, ética-moral, estética, espiritual, y sociopolítica del ser humano (ACODESI, 2003). Lo anterior posibilitó el desarrollo de diálogos interepistémicos que "generaron 
cambios de actitudes hacia las cosas" (Trujillo, 2002, p. 408; Quintana Arias, 2017a, p. 937) y "permitieron la emancipación de la etnia Tikuna, a través de cambios en los estudiantes" (Quintana Arias, 2017b, p. 100), referentes a su microética, micropolítica y microrevoluciones o cambios de comportamiento frente a la imposición de una cultura sobre otra.

El diálogo interepistémico entre la interculturalidad y la enseñanza llevó al enfoque de pedagogía crítica hacia una pedagogía descolonizadora que reivindicó campos de ser, poder y saber en la vida (Walsh, 2007). Esto se evidenció en las narraciones de los estudiantes sobre la experiencia, que no solo estuvieron condicionadas por el contexto de la clase sino reconocidas por su familia, como lo observa Bruner y Weisser (1995), "la importancia de la familia [es fundamental] para el manejo de la autoconciencia y la acción, así como [para] la responsabilidad y la individualidad" (p. 187).

La enseñanza del inglés desde los mitos Tikuna para la solución del conflicto intercultural bilingüe expone una línea de fuga o alternativa local que contribuye a la emancipación de una etnia indígena colombiana, al romper la uniformidad de la globalización. En consecuencia, los procesos socio-semánticos con la elaboración de guiones y ejercicios de simulación reconocen nuevos conceptos a través de situaciones cotidianas de una de las poblaciones e idiomas locales que no se contemplan en los modelos tradicionales de aprendizaje, restructurando la biología del significado a través de relatos que subjetivan la realidad (Bruner y Weisser, 1995).

Visualizar la clase de inglés como un espacio emancipatorio intercultural "estimula al estudiante a abrir su mente, a aceptar, a comprender nuevas culturas y a promover el intercambio entre diferentes sociedades" (MEN, 2006, p. 9) en las que la enseñanza del inglés forja un tejido interdisciplinar con docentes que no solo hablan la lengua extranjera, sino que son promotores de competencias socioemocionales y sociolingüísticas que refuerzan la riqueza y diversidad del territorio para reafirmar comportamientos, actitudes y aptitudes que permitan generar cambios a través de microrevoluciones de conducta que Sercu (2005) ha enmarcado dentro de la competencia comunicativa intercultural (CCI).

La CCI integra la lengua y la cultura en la enseñanza de las lenguas (Paricio Tato, 2014), lo que involucra el desarrollo de la competencia socioemocional y sociolingüística al promover "la capacidad de relacionarse, la sensibilidad, la posibilidad de superar las relaciones estereotipadas" (MEN, 2006, p. 12). De esta manera, la propuesta evidencia microrevoluciones de conducta, a partir de la articulación de cosmovisiones, con el objeto de generar una sociedad intercultural, que no solo responden a la lógica del mercado a través de la biopolítica (Foucault, 2016) sino a las lógicas de una zoepolítica (Braidotti, 2009) que favorece el respeto y la dignidad por la vida al propiciar el aprendizaje autónomo intercultural a partir de las emociones.

Generar un escenario de encuentro de habilidades blandas o socioemocionales y duras cognitivas (Prada y Rucci, 2015; Quintana Arias, 2018; 2019a; 2019b) lleva a generar fundamentos conceptuales y herramientas metodológicas que contribuyen a la construcción colectiva de tejidos interdisciplinares superando así el paradigma de Bourdieu (2010) sobre la cultura legítima, en la que el estudiante tiene éxito cuanto más cerca esté de las lógicas impuestas, dejando atrás un curriculum de códigos culturales dominantes (Magendzo, 1986).

Lo anterior permitió que los estudiantes dejaran de ser ajenos a realidades regionales indígenas del trapecio amazónico colombiano, para darle sentido a lo pluriétnico y multicultural que se contempla en la Constitución Política de 1991 a través de una (1) de las sesenta y cinco (65) lenguas indígenas de Colombia (Tikuna) y dos de los setenta (70) idiomas propios del territorio (español-tikuna) (ONIC, 2015), mediante la enseñanza de una lengua extranjera que es considerada la segunda lengua oficial del territorio (inglés) (Constitución Política de Colombia, 1991), y que se relaciona con el objetivo 4 de la ONU: "garantizar una educación inclusiva, equitativa y de calidad y promover oportunidades de aprendizaje durante toda la vida para todos" (ONU, 2015, p. 1). 
De esta manera, la biopolítica, la vida cotidiana y la interculturalidad hacen de la clase de inglés, vista desde la $\mathrm{CCl}$, no sólo un espacio de enseñanza de la cultura extranjera, también un ambiente intercultural de construcción de sociedad con conciencia ambiental en el que se valora, reflexiona, recupera y revitaliza sobre lo pluriétnico y multicultural local (Quintana Arias, 2020) para trasformar, identificar y re-conceptualizar, a partir de lo decolonial, ontologías y epistemologías en la construcción de estructuras éticas que rompan estereotipos; en palabras de Dussel: "confirman la razón del otro y contemplan la crítica a las razones violentas, coercitivas y genocidas" (1993, p. 66).

\section{Conclusiones}

La enseñanza de la lengua inglesa y los mitos Tikuna desde el enfoque intercultural sirvieron como herramienta para la mitigación del conflicto intercultural bilingüe en un grupo de estudiantes de grado 11 de un colegio público de Bogotá, a través de una propuesta de aprendizaje guiado que relaciona la biopolítica, la vida cotidiana y la interculturalidad, y su incidencia en la enseñanza del inglés como una forma de despertar la microética, la micropolítica y las microrevoluciones de conducta que combaten la extinción gradual y sistemática de la riqueza pluriétnica y multicultural local.

La necesidad educativa en un país en el que se están perdiendo idiomas tradicionales hace de la enseñanza de los mitos Tikuna una estrategia que aporta a la solución al conflicto intercultural bilingüe. De esta manera, la propuesta es una posibilidad de generar nuevos espacios de glocalización que movilize conocimientos más allá del aprendizaje pragmático, y así poder rescatar costumbres locales e idiomas para visibilizarlos y poner en juego sus palabras y formas gramaticales, lo que permite contribuir a la $\mathrm{CCI}$ al ver el mundo de una manera diferente y no estereotipada que aporta al desarrollo de la identidad cultural local.

La ruta metodológica del instrumento pedagógico de Plantas Medicinales del Amazonas (PMA) propició el aprendizaje intercultural que permitió trasladar la enseñanza del inglés desde el enfoque del interculturalismo funcional hacia el interculturalismo crítico, generando la apropiación de la diversidad cultural de una etnia indígena colombiana por medio de mitos o formas históricas culturales para relacionarse con el territorio.

La propuesta nació de los estudios previos de uno de los autores de este escrito, los cuales han contribuido a avanzar en la investigación sobre la enseñanza del inglés y la competencia sociolingüística e intercultural, situando el conflicto intercultural bilingüe como una tensión entre la zoepolítica y la biopolítica. De esta manera, en la propuesta subyace la importancia del enfoque postestructuralista en una escuela que no solo tiene el potencial de exponer líneas de fuga para posibilitar otras formas de ser con el mundo y con los otros, sino de fomentar ciudadanos críticos y éticos que trasciendan las lógicas de mercado y sitúen sobre lo local valores negados que fortalezcan la identidad nacional.

Pese a la imposición de la enseñanza de la lengua inglesa sobre las locales, la clase de inglés es un escenario intercultural por naturaleza donde se encuentran la diversidad y la posibilidad de construir y reconstruir sociedades a partir de competencias socio-lingüísticas como un acto intercultural que nace de la interacción humana, y que favorece los encuentros y la potencialidad de responder a las necesidades y demandas de todos sin violentar a nadie.

La vida cotidiana bajo la lógica del inglés como una lengua global en un país multiétnico y pluricultural como Colombia puede hacer ver a la enseñanza del inglés como una estrategia biopolítica de dominación que, desde una mirada crítica, permite crear realidades, sociedades e identidades que ven en esta estrategia otra forma de relacionarse con la vida, lo que expone la resistencia de lo local ante lo global y una línea de fuga relacionada con la zoepolítica.

La propuesta evidenció la posibilidad de forjar tejidos interdisciplinares a través de objetivos interculturales entre la educación ambiental y el currículo, con docentes que promueven la adquisición de una competencia comunicativa 
intercultural (CCI), reforzando de esta manera la apreciación por la riqueza y la diversidad del territorio para trasformar comportamientos, actitudes y aptitudes, que permiten generar cambios a través de microrevoluciones de conducta que van en favor del respeto por la vida.

\section{Referencias}

ACODESI. (2003). La formación integral y sus dimensiones: texto didáctico. Editorial Kimpres Ltda. http://www.acodesi.org.co/es/images/Publicaciones/ pdf libros/texto didactico_negro.pdf

Albó, X. (2002). Iguales aunque diferentes: hacia unas políticas interculturales y lingüísticas para Bolivia. Ministerio de Educación.

Alonso, A. (2006). La competencia intercultural en la enseñanza del inglés dentro del contexto turístico. Revista de investigación e innovación en la clase de lenguas, 7(10), 17-26.

Bégout, B. (2005). La découverte du quotidien. Allia.

Bourdieu, P. (2010). Distinction: A social Critique of the Judgement of Taste. Routledge.

Braidotti, R. (2009). Transposiciones: Sobre la ética nómada. Gedisa Editorial.

Bruner, J., \& Weisser, S. (1995). La invención del yo: la autobiografía y sus formas. En D. Olson $\varepsilon N$. Torrance (Eds.), Cultura escrita y oralidad (pp.. 177202). Gedisa.

Byram, M., Gribkova, B., \& Starkey, H. (2002). Developing the Intercultural Dimension in Language Teaching: A Practical Introduction for Teachers. Council of Europe. Strasbourg, France. https://rm.coe. int/16802fc1c3

CNMH. (2014). Guerrilla y población civil. Trayectoria de las FARC 1949-2013. Centro Nacional de Memoria Histórica. http://www.centrodememoriahistorica.gov. co/descargas/informes2013/farc/guerrilla-poblacioncivil.pdf

Constitución Política de Colombia. (1991). http:// www.secretariasenado.gov.co/senado/basedoc/ constitucion_politica_1991.html

Cornejo, J. (2012). Educación, interculturalidad y ciudadanía. Educar em Revista, 43, 239-254. https:// doi.org/10.1590/S0104-40602012000100016

Durkheim, É. (2014). Educación y sociología. Ediciones Coyoacán.

Dussel, E. (1993). Eurocentrism and Modernity (Introduction to the Frankfurt Lectures). Boundary 2, 20(3), 65-77. https://doi.org/10.2307/303341
Eberhard, D., Simons, G., \& Fenning, C. (2019). Ethnologue: Languages of the World. SIL International.

Eisenhardt, K. M. (1989). Building Theories from Case Study Research. The Academy of Management Review, 14(4), 532-550. https://doi. org/10.2307/258557

Foucault, M. (1992). Microfísica del poder (J. Varela \& F. Alvarez-Uría, Eds). La Piqueta.

Foucault, M. (2016). Nacimiento de la biopolítica: Curso del Collège de France (1978-1979) (F. Ewald, A. Fontana \& M. Senellar, Eds). Akal.

Guido, S. P. (2013). Experiencias de educación indígena en Colombia: entre prácticas pedagógicas y políticas para la educación de grupos étnicos. Universidad Pedagógica Nacional.

Guilherme, M. (2004). Intercultural competence. En Michael Byram (Ed.), Routledge Encyclopedia of Language Teaching and Learning (pp. 298-300). Psychology Press.

Gyepi-Garbrah, J. V. (2010). Understanding Diversity and Interculturalism Between Aboriginal Peoples and Newcomers in Winnipeg [Tesis de Maestría, University of Saskatchewan]. Repositorio institucional University of Saskatchewan. https://harvest.usask. ca/bitstream/handle/10388/etd-12272010-203845/ FinalThesis2010jvgg.pdf

Jennings, J. (2011). Globalizations and the ancient world. Cambridge University Press.

Key, D. (1998). Literacy Shutdown: Stories of Six American Women. International Reading Association.

Kymlicka, W., \& Castells, C. (1996). Ciudadanía multicultural: Una teoría liberal de los derechos de las minorías (Estado y Sociedad). Barcelona: Ediciones Paidós.

Luque, B. (2008). Enfoques actuales usados en la enseñanza de segundas lenguas. Letras (Caracas), 50(76), 183-209.

Magendzo, A. (1986). Currículum y cultura en América Latina. Programa Interdisciplinario de Investigaciones en Educación (PIIE). http://www.piie.cl/biblioteca/ publicaciones/libros/L-1986-044.pdf

Majhanovich, S., Fox, C., \& Kreso, A. P. (2009). Living Together Education and Intercultural Dialogue. Springer Netherlands.

Ministerio de Educación Nacional [MEN]. (2006). Estándares Básicos de Competencias en Lenguas Extranjeras. https://www.mineducacion.gov.co/1759/ articles-115174_archivo_pdf.pdf 
Morimoto, Y., Lucero, M. V. P., \& Martínez, R. S. (2015). La enseñanza de ELE centrada en el alumno. Asociación para la Enseñanza del Español como Lengua Extranjera. https://dialnet.unirioja.es/servlet/ libro? codigo $=581025$

Omaggio, A. (2001). Teaching Language in Context (3rd ed.). Heinle $\&$ Heinle.

ONIC. (27 de febrero de 2015). 65 Lenguas Nativas de las 69 en Colombia son Indígenas. https://www.onic. org.co/noticias/636-65-lenguas-nativas-de-las-69en-colombia-son-indigenas

ONU. (18 de noviembre de 2014). Idiomas oficiales. https:// www.un.org/es/sections/about-un/official-languages/

ONU. (01 de enero de 2015). Objetivo 4: Garantizar una educación inclusiva, equitativa y de calidad y promover oportunidades de aprendizaje durante toda la vida para todos. https://www.un.org/ sustainabledevelopment/es/education/

Paricio Tato, M. S. (2014). Competencia intercultural en la enseñanza de lenguas extranjeras. Porta Linguarum: revista internacional de didáctica de las lenguas extranjeras, 21, 215-226.

Prada, M., E Rucci, G. (01 de julio de 2005). Instrumentos para la medición de las habilidades de la fuerza de trabajo. Publications Banco Interamericano de Desarrollo. https://publications.iadb.org/ publications/spanish/document/Instrumentos-parala-medici\%C3\%B3n-de-las-habilidades-de-la-fuerzade-trabajo.pdf

Quintana Arias, R. F. (2015). La escuela occidental: mediadora de una estabilidad territorial al revalorizar el universo indígena. Bio-Grafía, 8(14), 67-82. https://doi. org/10.17227/20271034.vol.8num.14bio-grafia67.82

Quintana-Arias, R. F. (2017a). La educación ambiental y su importancia en la relación sustentable: HombreNaturaleza-Territorio. RLCSNJ, 15(2), 927-949.

Quintana Arias, R. F. (2017b). Relación entre los niños de una comunidad indígena con la naturaleza y el Amazonas. Revista Educación y Desarrollo Social, 11(2), 90-107. https://doi.org/10.18359/reds.3244

Quintana Arias, R. F. (2018). Etnodesarrollo y Medio Ambiente. Editorial Académica Española. https://www. eae-publishing.com/catalog/details//store/es/book/978620-2-10167-7/etnodesarrollo-y-medio-ambiente

Quintana Arias, R. F. (2019a). Body, Culture and Education: Dance as a Curricular Game Material and Formation Tool for Peace. En L. Gómez Chova, D. López Martínez \& I. Candel Torres (Eds.), ICERI 2019: 12th International Conference of Education, Research and Innovation. Seville, (Spain). 1113 November, 2019 (pp. 11186-11193). IATED Academy.
Quintana Arias, R. F. (2019b). La danza en las dimensiones del ser humano y los contenidos escolares. Plumilla Educativa, 23(1), 93-120. https://doi.org/10.30554/ plumillaedu.1.3349.2019

Quintana Arias, R. F. (20 de marzo de 2020). Blending English and Traditional Cultures in Colombia. Bilingualism (Fall/Winter 2019-2020). https://revista. drclas.harvard.edu/blending-english-and-traditionalcultures-in-colombia/

Quintero, J., E Torres, F. (2010). Narrativa pedagógica universitaria. Un lente transformador. Universidad de Caldas.

Rojas Fabris, M. T. (2018). Inclusión social: miradas de los docentes y apoderados frente a la mixtura social en sus escuelas. Estudios pedagógicos (Valdivia), 44(3), 217-234. https://doi.org/10.4067/S0718$\underline{07052018000300217}$

Rojas, J., Quisbert, N., Arrieta, J., \& Arrechondo, J. (2007). Educación Intercultural y Bilingue. Universidad Saleciana.

Rother, T. (2005). Conflicto intercultural y educación en Chile: desafíos y problemas de la Educación Intercultural Bilingüe (EIB) para el pueblo Mapuche. Revista Austral de Ciencias Sociales, 9, 71-84.

Ruiz, A. (2016). Semiología de la vida cotidiana. [Notas de los Cursos de semiología de la vida cotidiana]. Siglo XXI.

Sercu, L. (2005). Foreign Language Teachers and Intercultural Competence: An Investigation in 7 Countries of Foreign Language Teachers' Views and Teaching Practices. En P. Bandura, L. Castro, L. Davcheva, M. Méndez \& P. Ryan (Eds.), Foreign Language Teachers and Intercultural Competence. An International Investigation (pp. 1-18). Multilingual Matters. https://doi.org/10.21832/9781853598456

Serrano, R. (2008). Guía de conocimiento sobre educación intercultural. Revista Gloobal Hoy, 1 (1), 1-9.

Soto, J. E. (2008). El currículo intercultural bilingüe la naturaleza humana integrada a su mundo cultural. Cooperativa Editorial Magisterio.

Soto, J. E. (2015). Filosofía de la Liberación Intercultural y Teoría Sociológica de la Práctica: Dos Fundamentos en la Construcción de Comunidades Bilingües. Amauta, 13(26), 111-128.

Tassin, E. (2001). La phénomenologie de l'action, une politique du monde. En H. Arendt, L'humaine condition politique. París: L’Harmatan.

Trujillo, F. (2002). Objetivos en la enseñanza de lenguas extranjeras: De la competencia lingüística a la competencia intercultural. En F. Herrera Clavero, F. Mateos Claros, S. Ramírez Fernández, $M$. 
Ramírez Salguero \& J. Roa Venegas, Inmigración, interculturalidad y convivencia (pp. 407-418). Instituto de Estudios Ceutíes. https://www.ugr. es/ ftsaez/aspectos/objetivos.pdf

Tubino, F. (2003). Del interculturalismo funcional al interculturalismo crítico. Centro de Recursos Interculturales, Ministerio de Cultura, Perú. https:// centroderecursos.cultura.pe/es/registrobibliografico/ del-interculturalismo-funcional-al-interculturalismocr\%C3\%ADtico

UNESCO. (2010). Atlas de las lenguas del mundo en peligro. http://www.unesco.org/languages-atlas/fr/ atlasmap.html
Useche, O., \& Pérez, C. (2019). Del pensamiento crítico de lo posible a la experimentación de nuevos modos de existir. Las resistencias obreras como vehículo de la irrupción del acontecimiento socialista. En R. García, C. Piedrahita, P. Vommaro \& O. Useche (Eds.), Alternativas críticas en estudios sociales (pp. 71-90). Universidad Distrital Francisco José de Caldas, CLACSO.

Walsh, C. (2007). Interculturalidad, colonialidad y educación. Revista Educación y Pedagogía, 48, 2535. 